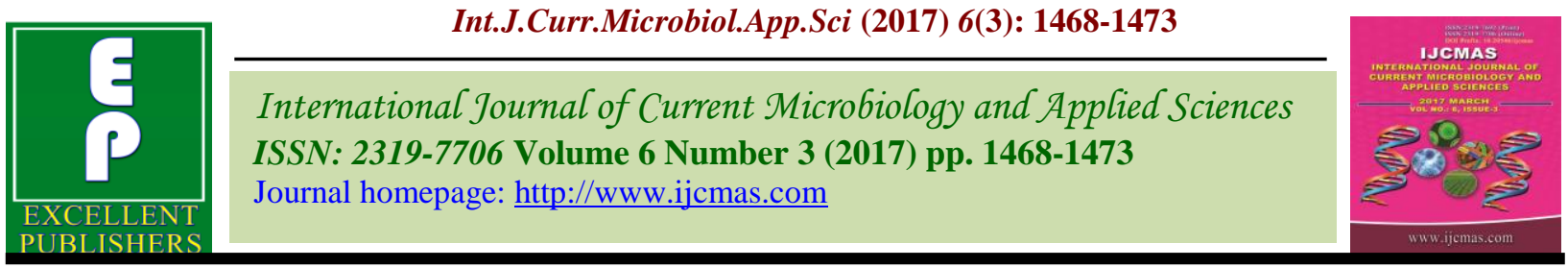

Original Research Article https://doi.org/10.20546/ijcmas.2017.603.168

\title{
Aflatoxin Contamination of Spices Sold Collected from Local Market in Tripoli
}

\author{
N. Essawet ${ }^{1}$, H. Abushahma ${ }^{2}$, S. Inbaia ${ }^{1 *}$, O.H. Elkwil ${ }^{3}$ and H.A. Amra ${ }^{4}$ \\ ${ }^{1}$ Azzaytuna University-Libya \\ ${ }^{2}$ Higher Institute of Agriculture Techniques, Al-Ghiran-Libya \\ ${ }^{3}$ Agriculture Bank District of Zliten., Libya \\ ${ }^{4}$ National Research Center, Egypt \\ *Corresponding author
}

\begin{tabular}{|c|c|}
\hline & A B S T R A C T \\
\hline & \multirow{7}{*}{ 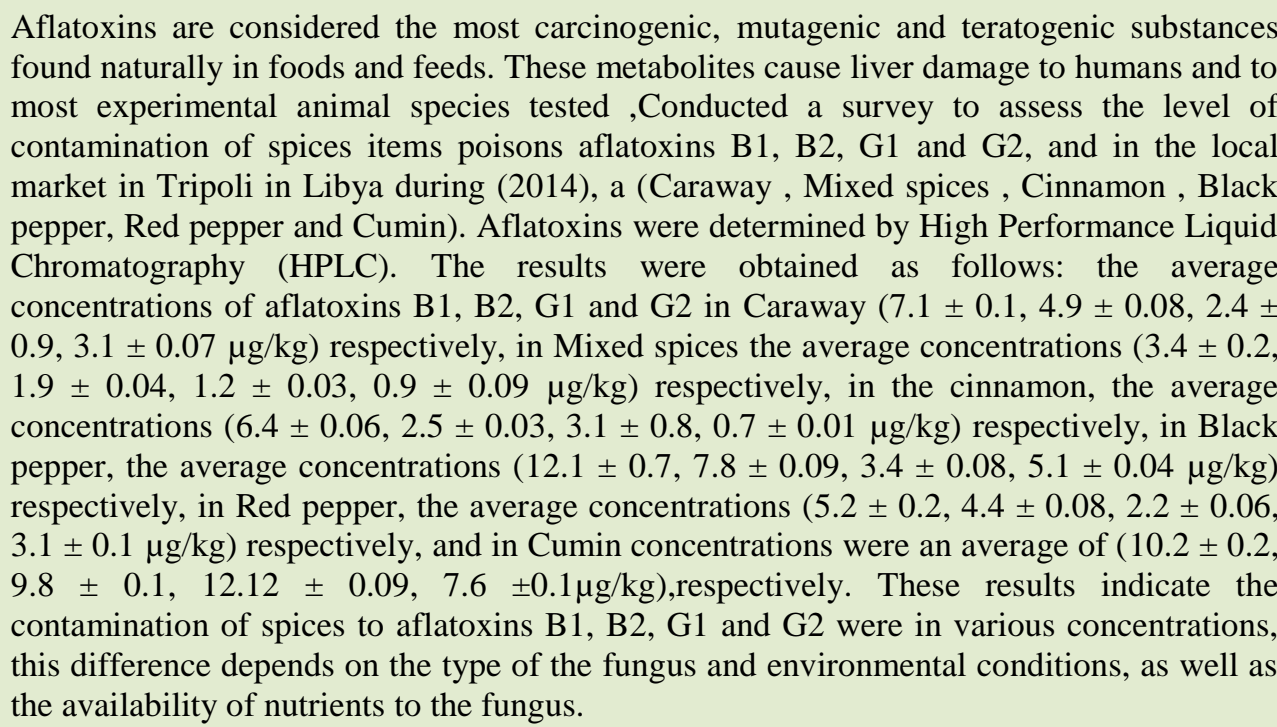 } \\
\hline Keywords & \\
\hline Spice, & \\
\hline $\begin{array}{l}\text { Tripoli, } \\
\text { Aflatoxins, } \\
\text { HPLC. }\end{array}$ & \\
\hline Article Info & \\
\hline $\begin{array}{l}\text { Accepted: } \\
22 \text { February } 2017 \\
\text { Available Online: } \\
10 \text { March } 2017\end{array}$ & \\
\hline & \\
\hline
\end{tabular}

\section{Introduction}

Foods are exposed to certain species of fungi that secrete organic compounds as their metabolites which mostly are poisonous for humans, animals and other microorganisms. The most important recorded fungi as toxin producers are Aspergillus, Fusarium and Penicillium species that produce various kinds of toxins the most important of are aflatoxins, ochratoxins, zearalinon and others. Those toxins are highly toxic compounds that cause many kinds of diseases including cancers.

Fungi have the capability to grow on all foods without an exception, whether their moisture content was high or low (although fungi growth requires moisture). Fungi grow on crops in the field and after crop harvest and storage, storage fungi grows on it. Fungi also 
grow within wide range of temperatures (15$35^{\circ} \mathrm{C}$ ) and causes the damage of these commodities due to what they exposed to from physical (in shape, texture, color, aroma and taste) and chemical (due to the fungal consumption of nutrients so lowering the food content of organic matter) changes in addition to the aflatoxins that they secret. That did not necessarily means that every fungi infected commodity is containing aflatoxins because fugal growth needs conditions different from that needed to produce toxins such as the moisture of the infected commodity, medium temperature, medium content of oxygen and other required conditions for fungi to grow and produce toxins. However, not every fungus has the genetic capacity to produce aflatoxins even he belongs to one species known with aflatoxins production due to the differences between the isolated strains from the same species which are accompanied with differences in the capability of toxin (s) production according to the genetic capacity. The same aflatoxins also may be produced by more than one of toxic fungal species (Anonymous, 2002). The popularity of hot peppers (Capsicum annuum L.), also known as chili peppers, as spices or vegetables and for other uses increases every year, powdered red pepper is one of the favorite spices in South Asia and is commonly used for flavoring, seasoning, and impart in aroma or coloring to foods. Hot peppers are the principal component of curry and chili powder and can be used to make pepper sauce, red pepper, and paprika (Iqbal et al., 2011)

Spices are often contaminated with mycotoxins. The climatic conditions prevailing in the tropics are especially favorable for mold contamination and mycotoxin production. Of the different mycotoxins, aflatoxin is the commonest contaminant in spices (Fazekas et al., 2005). Peppers are very susceptible to aflatoxin contamination, which is affected by atmospheric temperature, humidity, insects, and drying and processing conditions. Mold contamination can occur in the field during crop production and during storage when conditions are favorable. Sun drying is a common post harvest practice in some countries, which involves spreading peppers on soil in a single layer. Because of the drying processes are on the soil, some peppers are contaminated with fungus (Iqbal et al., 2011 and Erdogan, 2004).

\section{Materials and Methods}

In this research, total of 54 samples of crushed spices (caraway, mixed spices, cinnamon, black pepper, red pepper and cumin) were collected from private markets at Tripoli city (Table 1). Samples were collected randomly and put into LDPE bags. Sample weight at collection was $1 \mathrm{~kg}$ and information about sample name, weight and date of collection were recorded on each bag. Samples were transferred under suitable conditions for storage and stored at $4^{\circ} \mathrm{C}$ until tests were carried out to assess the kinds of aflatoxins.

The assessment steps begin with subsampling, preparation and good blending of $25 \mathrm{~g}$ subsample, extraction with methanol: water (70:30) mixture and filtration through Watman no 4 filter paper. The resulted filtrate was passed through immunoaffinity column and eluted with methanol 100\%. Quantitative assessment was carried out on HPLC chromatograph with the following technical specifications:

The HPLC equipment was a Shiseido (SI-2) system with 3023 pump, 3023 autoinjector and fluorescence detector set at $360 \mathrm{~nm}$ for excitation and $460 \mathrm{~nm}$ for emission. A

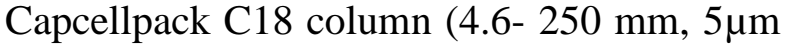
particle size, Shiseido, Japan) was used. The 
mobile phase was distilled water: methanol: acetonitril $(65: 25: 10)$ with a flow rate of 1 $\mathrm{ml} / \mathrm{min}$.

\section{Results and Discussion}

Spices are considered from the agricultural crops that expose to the fungal infection especially with aflatoxins producing fungi. In this research, aflatoxins were assessed and the results in table 2 and figure 1 show that the maximum concentration of Afla B1 was in Black pepper samples $(12.1 \pm 0.7 \mu \mathrm{g} / \mathrm{kg})$ and the minimum concentration was in Mixed spice samples $(3.4 \pm 0.2 \mu \mathrm{g} / \mathrm{kg})$. The maximum concentration of Afla B2 was in Cumin samples $(10.2 \pm 0.1 \mu \mathrm{g} / \mathrm{kg})$ as well as the maximum concentrations of Afla G1 and G2 that was found in Cumin samples also $(12.12 \pm 0.09$ and $7.6 \pm 0.1 \mu \mathrm{g} / \mathrm{kg}$, respectively).

The results demonstrated that aflatoxins were present in various concentrations in the different kinds of spice samples as a result of the growth of the productive fungi and the availability of suitable moisture and temperature for fungal growth. From table 3 and figure 2 , it indicated that extracting aflatoxins by immunoaffinity columns is a sensitive and highly accurate method with a recovery rate up to $86 \%$. The climatic conditions prevailing in the tropics are especially favorable for mold contamination and mycotoxin production. Of the different mycotoxins, aflatoxin is the commonest contaminant in spices (Fazekas et al., 2005).

Peppers are very susceptible to aflatoxin contamination, which is affected by atmospheric temperature, humidity, insects, and drying and processing conditions. Mold contamination can occur in the field during crop production and during storage when conditions are favor- able. Sun drying is a common postharvest practice in some countries, which involves spreading peppers on soil in a single layer. Because of the drying processes are on the soil, some peppers are contaminated with fungus (Iqbal et al., 2011 and Erdogan, 2004).

Substantial aflatoxin contamination of ground red pepper has been reported from Ethiopia, where eight of 60 samples collected from markets, shops and storage facilities were contaminated with AFB1 in concentrations of $250-525 \mu \mathrm{g} \mathrm{kg}$ (Fufa and Urga, 1996).

Table.1 The common and scientific names of spices that sampled from private markets

\begin{tabular}{|c|c|}
\hline Common name & Scientific name \\
\hline Caraway & Carum carvi $\mathrm{L}$. \\
\hline Mixed spices & Eucalyptos globulus $\mathrm{L}$. \\
\hline Cinnamon & Cinnamonum verum Presel \\
\hline Black pepper & Piper nigrum $\mathrm{L}$ \\
\hline Red pepper & Capsicum frutescens $\mathrm{L}$. \\
\hline Cumin & Cuminum cuminum \\
\hline
\end{tabular}


Table.2 Average concentrations of positive samples within the different kinds of spices

\begin{tabular}{|c|c|c|c|c|c|}
\hline \multirow{2}{*}{ Sample } & \multirow{2}{*}{$\begin{array}{c}\text { Positive } \\
\text { samples }\end{array}$} & \multicolumn{4}{|c|}{ Average concentration of aflatoxins $\boldsymbol{\mu g} / \mathbf{k g}$} \\
\cline { 3 - 6 } & Afla B1 & Afla B2 & Afla G1 & Afla G2 \\
\hline Caraway & 5 & $7.1 \pm 0.1$ & $4.9 \pm 0.08$ & $2.4 \pm 0.9$ & $3.1 \pm 0.07$ \\
\hline Mixed spices & 4 & $3.4 \pm 0.2$ & $1.9 \pm 0.04$ & $1.2 \pm 0.03$ & $0.9 \pm 0.09$ \\
\hline Cinnamon & 6 & $6.4 \pm 0.06$ & $2.5 \pm 0.03$ & $3.1 \pm 0.8$ & $0.7 \pm 0.01$ \\
\hline Black pepper & 4 & $12.1 \pm 0.7$ & $7.8 \pm 0.09$ & $3.4 \pm 0.08$ & $5.1 \pm 0.04$ \\
\hline Red pepper & 6 & $5.2 \pm 0.2$ & $4.4 \pm 0.08$ & $2.2 \pm 0.06$ & $3.1 \pm 0.1$ \\
\hline Cumin & 4 & $10.2 \pm 0.2$ & $9.8 \pm 0.1$ & $12.12 \pm$ & $7.6 \pm 0.1$ \\
\hline
\end{tabular}

Table.3 Average recovery rate for each aflatoxin (B1, B2, G1 and G2) that was added to red pepper sample at a concentration of $5 \mu / \mathrm{kg}$

\begin{tabular}{|c|c|c|c|c|}
\hline \multirow{2}{*}{ Sample } & \multicolumn{4}{|c|}{ Average recovery rate (\%) } \\
\cline { 2 - 5 } & Afla B1 & Afla B2 & Afla G1 & Afla G2 \\
\hline Caraway & $81 \pm 0.31$ & $82 \pm 0.85$ & $85 \pm 0.92$ & $77 \pm 0.30$ \\
\hline Mixed spices & $83 \pm 0.53$ & $86 \pm 0.30$ & $81 \pm 0.26$ & $75 \pm 0.55$ \\
\hline Cinnamon & $79 \pm 0.47$ & $84 \pm 0.22$ & $79 \pm 0.45$ & $73 \pm 0.61$ \\
\hline Black pepper & $80 \pm 0.35$ & $78 \pm 0.48$ & $78 \pm 0.65$ & $71 \pm 0.67$ \\
\hline Red pepper & $83 \pm 0.46$ & $80 \pm 0.57$ & $81 \pm 0.23$ & $72 \pm 0.34$ \\
\hline Cumin & $84 \pm 0.52$ & $85 \pm 0.54$ & $79 \pm 0.83$ & $70 \pm 0.75$ \\
\hline
\end{tabular}


Figure.1 Average concentration of aflatoxins $(\mu \mathrm{g} / \mathrm{kg})$ in the different kinds of spices

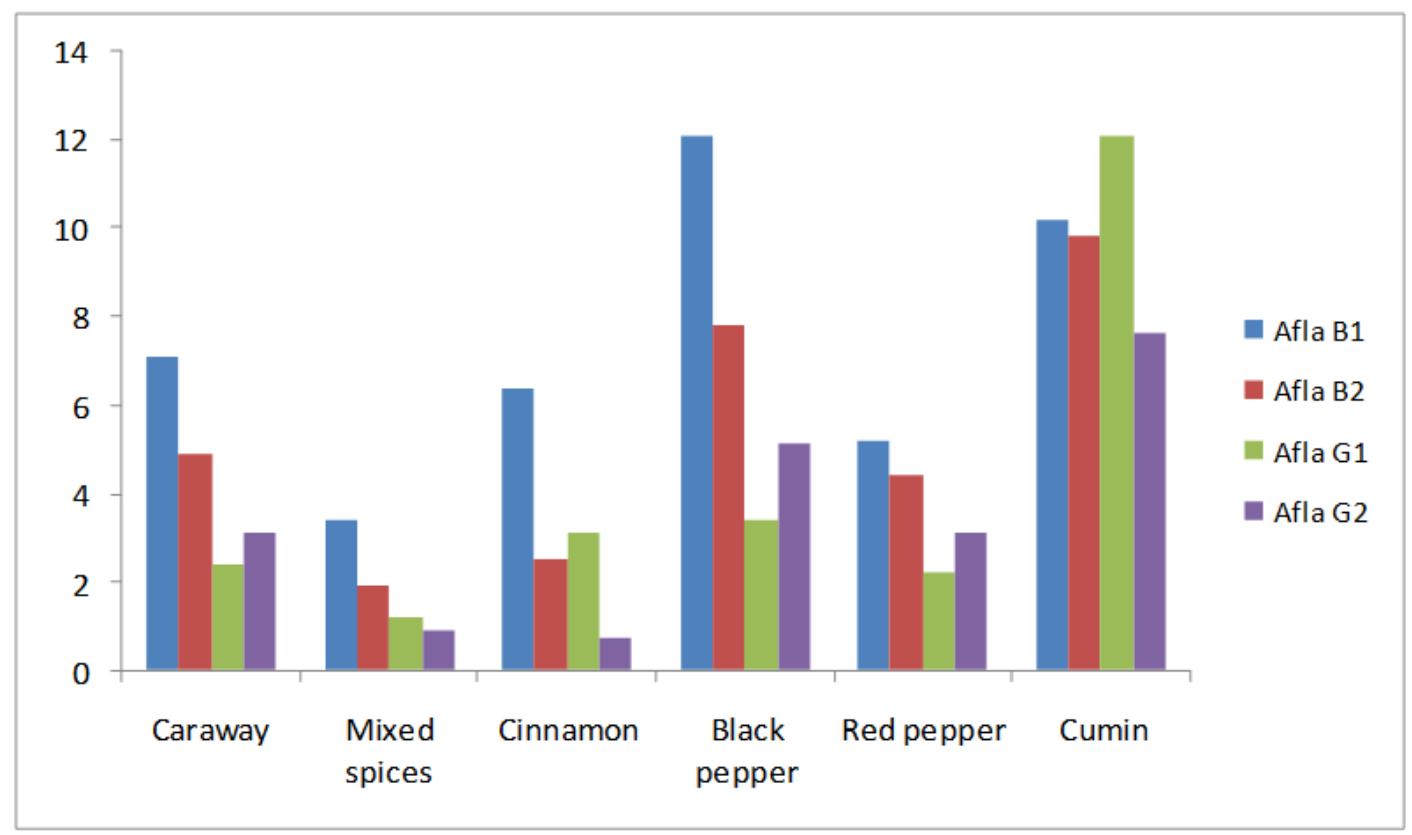

Figure.2 Average recovery rate (\%) for aflatoxins

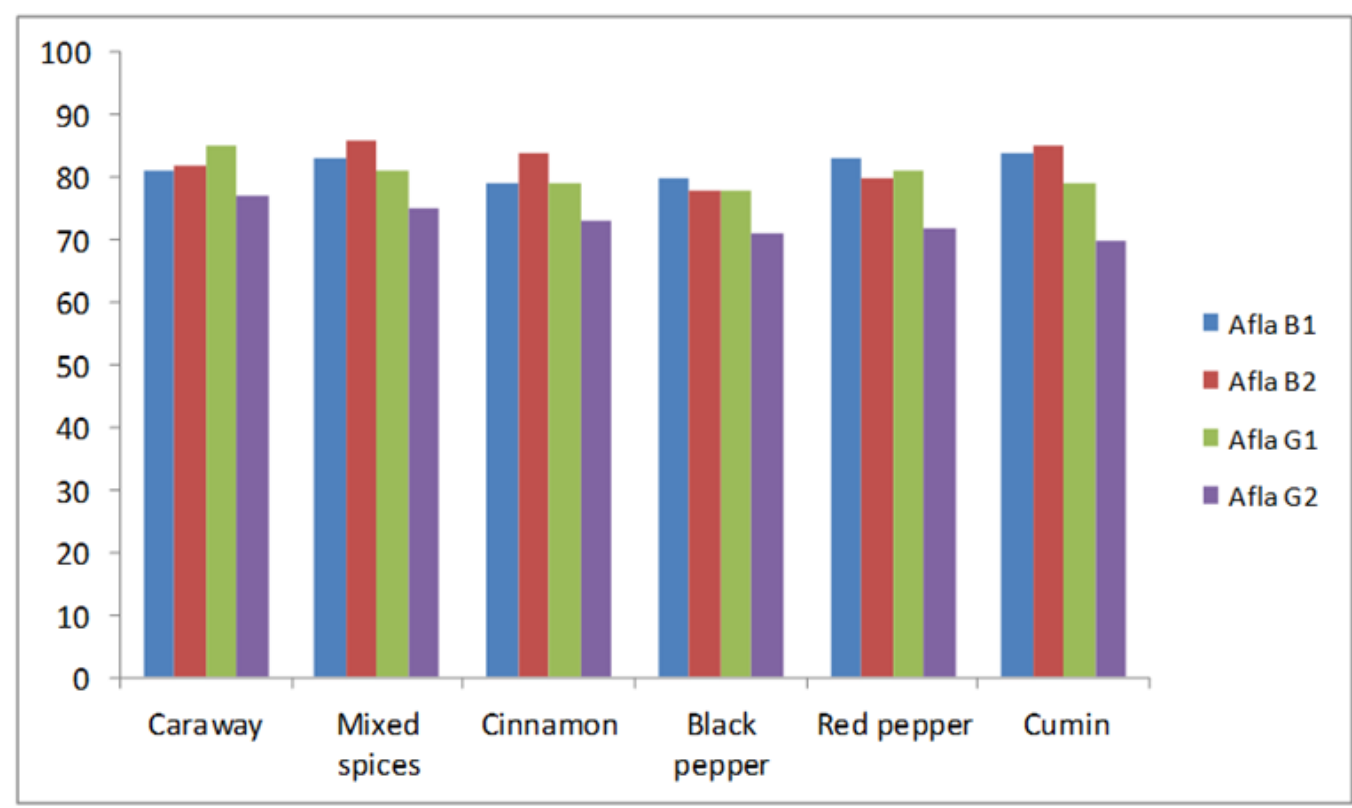

In Turkey, $24 \%$ and $13 \%$ of samples of different pepper types contained 7.5-200 (Demircioglu and Filazi, 2010) and 1.1-97.5 $\mu \mathrm{g} \mathrm{kg}$ (Erdogan, 2004) total aflatoxins, respectively. Elshafie et al., (2002) were surveyed one hundred and five samples of seven spices (cumin, cinnamon, clove, black pepper, cardamom, ginger, and coriander) for the mycoflora and AFs in the Sultanate of Oman. Twenty fungal species were isolated in 
which A. flavus, A. niger. Penicillium, Rhizopus, and Syncephalastrum racemosum were the most dominant. Of the seven spices studied, clove was found to be the least contaminated, while cumin was the most contaminated. None of the 15 selected samples of the spices contaminated by $A$. flavus were found to contain AFs (Elshafie et al., 2002). Cooking revealed that the aflatoxin content of spices did not decrease (MacDonald and Castle, 1996).

Although the mold A. flavus grows well on the spices, the production of AFs is lower than in cereals. This indicates that spices are not an ideal substrate for AF formation. It has been shown that essential oils extracted from spices, e.g. cloves, can inhibit mold growth and AF production completely. According to some reports, fungal growth was weak on curcumin, black pepper and white pepper and no AF was detected in black or white pepper after 10 days at $25{ }^{\circ} \mathrm{C}$. According Martins et al., (2001), the results of the survey indicate that there is little evidence for significant $\mathrm{AF}$ contamination in spices. The majority of samples contained AFs at low levels and others were negative (cardamom, cloves, ginger and mustard). In the meat industry (sausage, dry cured ham, luncheon meat) and in confection of ethnic dishes, $\mathrm{AF}$ contamination of spices is probably not relevant as a direct health hazard (Martins et al., 2001).

\section{References}

Anonymous. 2002. Commission Regulation
(EC) No 472/2002. Official J. European Communities, 45: 42-44.

Demircioglu, S., and Filazi, A. 2010. Detection of aflatoxin levels in red pepper produced in Turkey. J. Vet. Med. Association, 81(2): 63-66.

Elshafie, A.E., Al-Rashdi, T.A., Al-Bahry, S.N., and Bakheit, C.S. 2002. Fungi and aflatoxins associated with spices in the Sultanate of Oman. Mycopathologia, 155: $155-160$.

Erdogan, A. 2004. The aflatoxin contamination of some pepper types sold in Turkey. Chemosphere, 56: 321325.

Fazekas, B., Tar, A., and Kovacs, M. 2005. Aflatoxin and ochratoxin A content of spices in Hungary. Food Additives and Contaminants, 22(9): 856-863.

Fufa, H., and Urga, K. 1996. Screening of aflatoxins in Shiro and ground red pepper in Addis Ababa. Ethiopian Med. J., 34: 243-249.

Iqbal, Q., Amjad, M., Asi, M.R., and Arino, A. 2011. Assessment of Hot Peppers for Aflatoxin and Mold Proliferation during Storage. J. Food Protection, 74(5): 830835.

MacDonald, S., and Castle, L. 1996. A UK retail survey of aflatoxins in herbs and spices and their fate during cooking. Food Additives and Contaminants, 13: 121-128.

Martins, M.L., Martins, H.M., and Bernardo, F. 2001. Aflatoxins in spices marketed in Portugal. Food Additives and Contaminants, 18(4): 315-319.

\section{How to cite this article:}

Essawet, N., H. Abushahma, S. Inbaia, O.H. Elkwil and Amra, H.A. 2017. Aflatoxin Contamination of Spices Sold Collected from Local Market in Tripoli. Int.J.Curr.Microbiol.App.Sci. 6(3): 1468-1473. doi: https://doi.org/10.20546/ijcmas.2017.603.168 